\title{
Indolent glioma: a cause of epilepsy
}

\author{
T K Y LEE, Y NAKASU, M A JEFFREE, ${ }^{*}$ A J MOLYNEUX, ${ }^{*}$ AND C B T ADAMS \\ Departments of Neurosurgery and ${ }^{*}$ Neuroradiology, The Radcliffe Infirmary, Oxford
}

SUMMARY We studied eight patients with indolent gliomas. In all eight cases, despite characteristic radiological features, there was a delay in diagnosis because of misinterpretation of the initial computed tomogram. These tumours are an important cause of epilepsy of childhood, and surgery may well alleviate the epilepsy and possibly achieve a long term 'cure'. Therefore it is important that a diagnosis is made early and the lesion completely excised.

Since the days of Penfield and Jasper ${ }^{1}$ varying types of operation and different selection criteria for surgery of epileptic patients have been advocated with variable results. Falconer suggested that successful long term cessation of epilepsy depends on finding and removing focal pathology. ${ }^{2}$

Over the last 15 years we have seen a group of patients with sizable indolent gliomas at this hospital. These children have all presented a diagnostic problem to the clinicians who first managed them. All the children have a lengthy history and the tumours all show characteristic radiological features. These patients constitute a group whose epilepsy may be successfully alleviated by surgery. It is our impression that this pathological entity has not received the attention that it deserves. These children have been referred from all parts of the United Kingdom because of our interest in epilepsy surgery. The true incidence, however, may be rather higher than the number suggests because we suspect the diagnosis is frequently missed.

\section{Case reports}

CASE 1

An 8 year old boy presented at the age of 3.5 years, with focal epilepsy. He was seen by a paediatrician and a paediatric neurologist in his home town and London. Various diagnoses were made including 'atypical absences' and 'drop attacks' of unknown cause. His fits remained poorly controlled and were occurring at a rate of three to 15 per day when seen by us. A plain skull radiograph showed scalloping of the inner table of the skull at the level of the coronal suture, just to the left of the midline (fig 1). A computed tomogram showed a low density lesion in the frontal lobe adjacent to the scalloping (fig 2). A

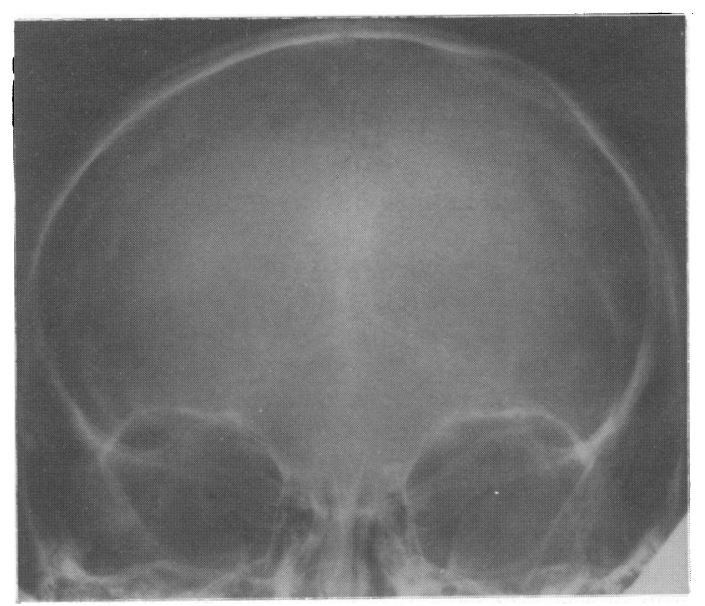

Fig 1 Case 1: skull radiograph showing scalloping of the inner table of the skull at the level of the coronal suture just to the left of the midline.

complete macroscopic excision of the lesion was performed. Intraoperative electrocorticography showed epileptic discharges associated with the lesion which ceased after excision. Histological diagnosis was that of a low grade glioma. During the early postoperative period he suffered one focal fit. When reviewed seven years later he was well, fit free, and attending a normal school.

CASE 2

A 10 year old Asian girl living in Scotland first presented at the age of 3 with tingling in her left foot, sometimes associated with a twitching movement of her left leg. A wide variety of anticonvulsants 


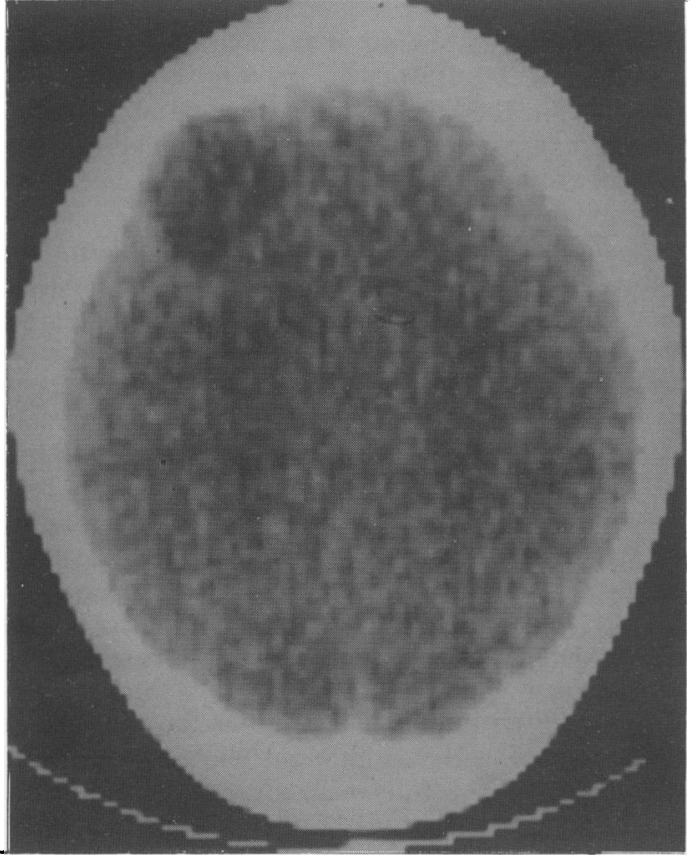

Fig 2 Case 1: computed tomogram showing a low density lesion in the frontal lobe adjacent to the scalloping.

including phenobarbitone, phenytoin, primadone, sodium valproate, and carbamazepine failed to control her attacks and she continued to have three to four fits per day. A skull radiograph was reported as normal and a computed tomogram showed a low density lesion in the right parietal lobe, thought to represent atrophy. Eventually she was referred to this hospital and on reviewing the skull radiographs and computed tomograms it was clear that this lesion was a space occupying lesion causing scalloping of the inner table of the skull (figs 3 and 4). At operation only a subtotal removal was possible as the lesion was situated in the central sulcus, extending to both motor and sensory cortex. Histology showed a protoplasmic astrocytoma. The patient was fit free for eight months before the attacks recurred. She had a full course of radiotherapy after which she had no seizures when reviewed four years later.

\section{CASE 3}

A 7 year old boy, born three months prematurely, first had right sided focal epilepsy at the age of 6 . He subsequently had a grand mal attack. A computed tomogram at Oxford was reported to show a parasagittal glioma. He was then referred elsewhere

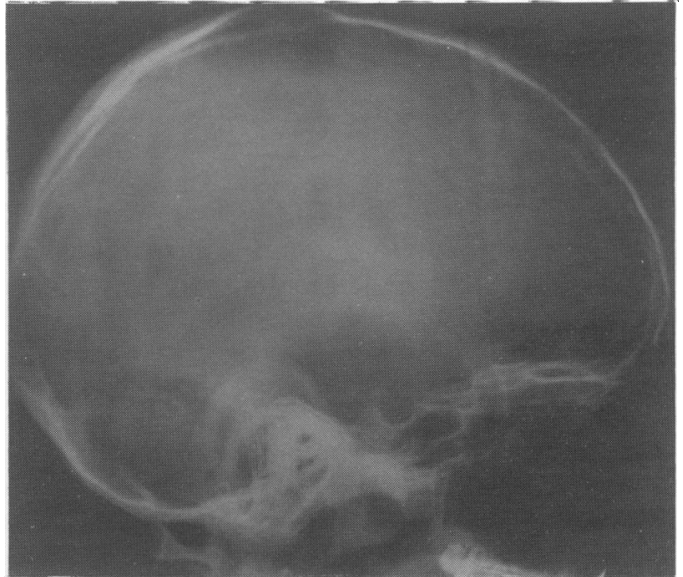

Fig 3 Case2:skull radiographshowingscalloping of the innertable of theskull.

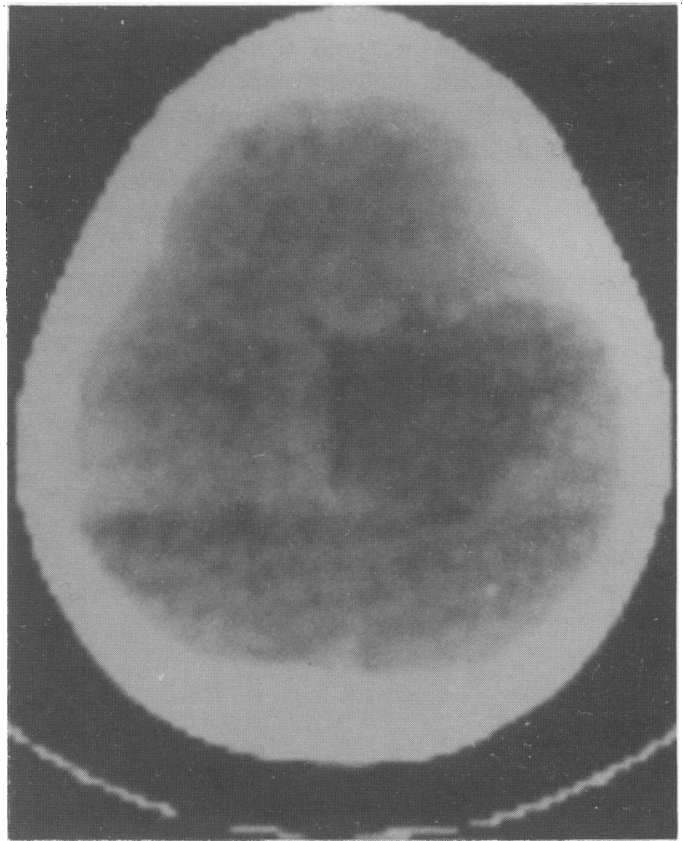

Fig 4 Case 2: computed tomogram showing a low density lesion. Scalloping was not apparent in the computed tomogram, which was of less than ideal quality.

to a paediatric neurosurgeon who regarded the lesion as atrophic. His epilepsy was poorly controlled with four to six attacks a day. He was eventually referred to this hospital where a subtotal removal of a tumour was carried out and histology shówed a grade 2 astrocytoma. Postoperative 
recovery was uneventful apart from slight residual weakness on the right side. He was fit free for the first six weeks after surgery but has subsequently had approximately one focal fit per month.

\section{CASE 4}

A 6 year old girl, born eight weeks prematurely, presented at the age of 3 years with psychomotor epilepsy. This responded initially to carbamazepine but later failed to be controlled by phenytoin, sodium valproate, and carbamazepine. Her electroencephalogram showed gross abnormalities with frequent paroxysmal discharges and a possible right sided focus. She had a computed tomogram when she was 4 years old, which showed an area of low density in the right frontal pole. This was thought, by a paediatric neurologist, to be due to extensive scarring, possibly due to old haemorrhage. She was referred to this hospital and a repeat computed tomogram showed scalloping of the inner table of the skull adjacent to the low density lesion in the right frontal lobe (fig 5). A frontal lobectomy was performed and the histology showed a low grade glioma. She was entirely free of epilepsy when seen seven months after her operation.

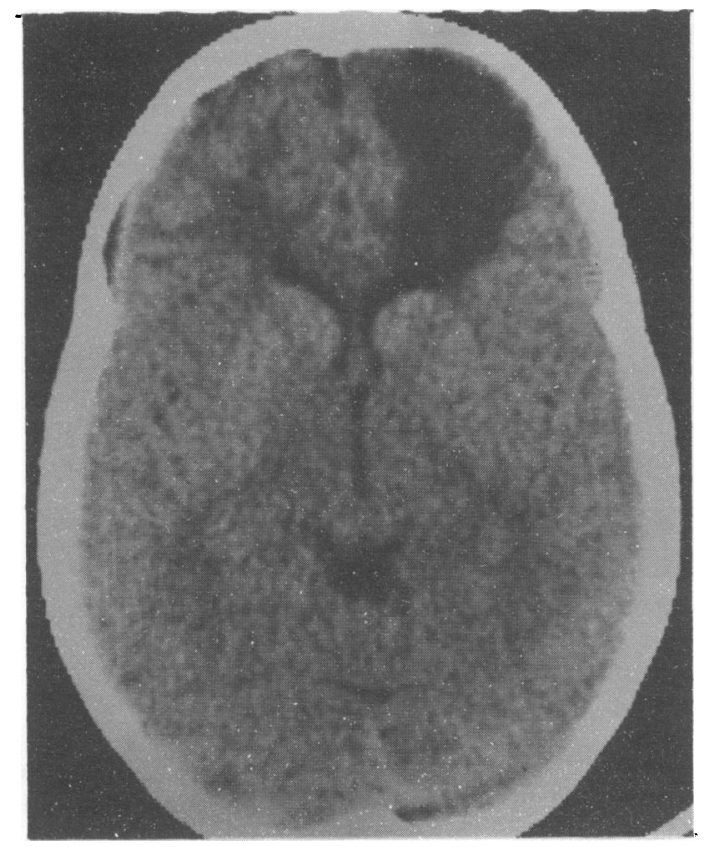

Fig 5 Case 4: computed tomogram showing scalloping of the inner table of the skull adjacent to a low density lesion in the right frontal lobe.
CASE 5

This boy first presented at the age of 3 years with absence attacks. By the age of 8 he began to have left sided focal epilepsy and by the age of 10 he had become aggressive and difficult to manage. He had been in trouble with the police and had been to a reform school. He was seen by various paediatricians and a paediatric neurologist. When seen by us at the age of 11 he was having one to three focal fits together with, on average, one grand mal fit per week. A plain skull radiograph showed thinning of the inner table of the skull in the left frontoparietal area. A computed tomogram showed a low density area just above the sylvian fissure extending fairly deeply half way between the vault and the falx cerebri. Complete macroscopic excision of the tumour was performed. Histology showed a grade 2 astrocytoma. Six years later he had had no further grand mal or focal epilepsy and was attending a normal school. His behaviour was much improved.

Since the writing of this paper we have had three more patients who had indolent gliomas presenting with epilepsy. The follow up after surgery was not long enough for them to be included in this series but they serve to illustrate further the clinical course and radiological features of indolent glioma.

\section{CASE 6}

An 8 year old boy first presented at the age of 5 with absence attacks and these developed into partial complex seizures. He was investigated with a computed tomogram on two ocsasions before being referred to us. Despite treatment he was having about 200 attacks per year. A repeat computed tomogram showed a high density lesion in the left temporoparietal lobe causing scalloping of the inner table. At operation the tumour was found to be straddling the sylvian fissure with vessels entering and leaving it. A total excision was therefore impossible. A biopsy of the tumour was carried out. Histology showed an oligodendroglioma. A left temporal lobectomy was also performed in the hope that this additional procedure would control his epilepsy. When reviewed three months after surgery he had had no fits.

\section{CASE 7}

A 13 year old boy presented at the age of 9 with an absence attack. Over the following year he developed grand mal epilepsy. A computed tomogram performed one year before admission showed a well defined area of a lower attenuation over the right parietal area with a small area of high density just superficial to it. This was thought to be the result of a previous haemorrhage from an underlying arter- 


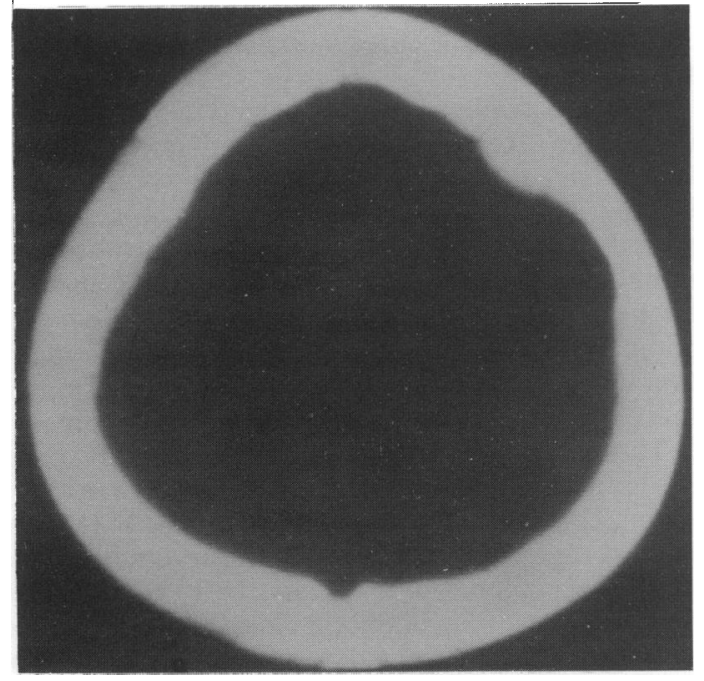

Fig 6 Case 7: computed tomogram set at the bone window which showed scalloping of the inner table of the skull adjacent to a tumour.

iovenous malformation. His fits were difficult to control and he had 63 fits during the week before admission. The computed tomogram performed at this hospital showed an indentation of the inner table of the skull just adjacent to the lesion (fig 6). Complete macroscopic excision of the lesion was performed and the histology was a low grade glioma. When seen six weeks after the operation he had had no further epilepsy.
CASE 8

A 13 year old left handed boy presented with epilepsy at the age of 8 . Over the previous five years he had had increasing fits, up to six times a day. His parents noticed that his writing and feeding with his left hand had become increasingly poor. Within the last one year he became progressively more aggressive and disobedient and somewhat disinhibited. At one time the possibility of pseudoseizure was raised because there was no abnormality shown on electroencephalography. The patient was referred for psychotherapy without improvement. He had a computed tomogram performed in another hospital, which showed a lesion over right posterior frontal region and this was considered inoperable. A repeat scan was performed at this hospital. This showed that the tumour was more localised than suggested by the scan done previously and it indented the inner table of the skull. At operation subtotal removal of the tumour was performed. During the early postoperative period he had two episodes of focal fits but remained fit free when reviewed three months later. His parents reported dramatic improvement in the patient's behaviour and that 'he is a new person'.

The details of the eight patients are summarised in the table.

\section{Discussion}

The striking characteristic of this group is the delay in diagnosis that resulted from the misinterpretation of the initial findings on computed tomography. In some cases the diagnosis of epilepsy proved difficult and alternative diagnosis of 'pseudoseizures', etc, were commonly made, which added to the distress

Table Details of eight patients studied

\begin{tabular}{|c|c|c|c|c|c|c|c|c|}
\hline & \multicolumn{8}{|l|}{ Case No } \\
\hline & 1 & 2 & 3 & 4 & 5 & 6 & 7 & 8 \\
\hline $\begin{array}{l}\text { Age of onset of first } \\
\text { fit (years) }\end{array}$ & $3 \cdot 5$ & 3 & 6 & 3 & 3 & 5 & 9 & 8 \\
\hline $\begin{array}{l}\text { Age at surgery } \\
\text { (years) }\end{array}$ & 9 & 10 & 7 & 6 & 11 & 8 & 13 & 13 \\
\hline $\begin{array}{l}\text { Delay in diagnosis } \\
\text { (years) }\end{array}$ & $4 \cdot 5$ & 7 & 1 & 3 & 7 & 3 & 4 & 5 \\
\hline Extent of excision & Complete & Subtotal & Subtotal & Complete & Complete & $\begin{array}{l}\text { Biopsy and } \\
\text { temporal } \\
\text { lobectomy }\end{array}$ & Complete & Subtotal \\
\hline Complication & Nil & Nil & $\begin{array}{l}\text { Mild hemiparesis } \\
\text { which improved }\end{array}$ & Nil & Nil & Nil & Nil & Nil \\
\hline $\begin{array}{l}\text { Follow up } \\
\text { Results }\end{array}$ & $\begin{array}{l}7 \text { years } \\
\text { No fits }\end{array}$ & $\begin{array}{l}7 \text { years } \\
\text { No fits }\end{array}$ & $\begin{array}{l}3 \text { years } \\
\text { Fit once per } \\
\text { month }\end{array}$ & $\begin{array}{l}6 \text { months } \\
\text { No fits }\end{array}$ & $\begin{array}{l}6 \text { years } \\
\text { No fits }\end{array}$ & $\begin{array}{l}3 \text { months } \\
\text { No fits }\end{array}$ & $\begin{array}{l}6 \text { weeks } \\
\text { No fits }\end{array}$ & $\begin{array}{l}3 \text { months } \\
\text { No fits }\end{array}$ \\
\hline
\end{tabular}

In cases 1-5 the mean age of onset of first fit was 3-7 years, mean age at surgery 8.4 years, mean delay in diagnosis 4.7 years, and mean follow up 5 years. 
of the patients and their parents. The area of low density on the computed tomogram was frequently incorrectly diagnosed as atrophic or ischaemic yet the indentation of the inner table of the skullwhich obviously is characteristic of a long standing, localised, space occupying lesion on the surface of the brain adjacent to the skull-was overlooked or unappreciated. This failure perhaps reflects undue concentration on the 'brain scan' as opposed to the 'head scan'; adjustment of the scan setting to show bone details is a particularly good method for showing the distortion of the inner table of the skull (fig 6). ${ }^{34}$

These patients also illustrate two other important facts: first, even subtotal removal of the tumour may produce extremely satisfactory alleviation of epilepsy and is worthwhile. Too many surgeons fail to consider the role of excisional surgery in treating the epilepsy and only assess the patient on the basis of excising the tumour in the hope of eradicating it. Thus when faced with a probable glioma all too often the surgeon retreats into surgical nihilism. This denies the patient and the family the chance of improvement or elimination of epilepsy, which is usually the predominant or sole symptom. On occasions it is possible to eradicate these tumours and such a chance should not be missed. This series reaffirms that the surgical treatment of epilepsy, that has withstood the test of time, is the removal of focal pathology-albeit incompletely on occasions.

It is incumbent on those surgeons treating epilepsy to emphasise the pathological, Oslerian principles of this surgery. All too often among the medical professions, surgical treatment of epilepsy is viewed as complex, difficult, time consuming, unsuccessful, dangerous, and requiring much expensive equipment. This partly accounts for the delay in referral among the patients whom we see in Oxford. In practice the vast majority of patients do not require complex investigation and the treatment is often straightforward and based on sound pathological precepts just as for any other surgical endeavour. A few patients may require prolonged and complex investigation but most do not. Patients with epilepsy due to a focal pathology should not be denied the possibility of surgery and its benefits and should be assessed by a neurosurgeon early. ${ }^{5}$

Secondly, this group also shows that if the epilepsy ceases after surgery then the behaviour of the patient rapidly improves and the child returns to normal. This improvement in behaviour cannot be ascribed to withdrawal of anticonvulsants as it is immediate and occurs despite maintenance of the same anticonvulsant regime. Family life returns to normal-parents can go out together, siblings can bring friends home again, quite apart from the patient being more able to live a normal existence. Indeed the family is cured as well as the patient after this surgery.

Is it impossible to make a correct diagnosis at an early stage? At least some of our patients were inferred to have a tumour from birth. This is supported by the observation of a palpable lump on one patient's head noticed shortly after birth by the mother. It was disregarded by her doctors and was later shown to have been caused by the expanding glioma. Thus a careful, detailed history and recognition of typical radiological features are important in the early diagnosis of these low grade gliomas.

The age of onset of epilepsy in our patients (cases 1-5) ranged from 3 to 8 years with a mean age of $3 \cdot 7$ years. The average age at diagnosis was 8.4 years. The average delay between initial presentation and surgery was therefore 4.7 years. In 1969 Page et al studied 23 cases of childhood glioma who presented with epilepsy and were detected late. ${ }^{6}$ The age of onset of seizures range from 3 months to 8 years and the delay in diagnosis ranged from five to 20 years. By then $90 \%$ of the patients had developed abnormal neurological signs. Pipemier reported on patients with low grade astrocytomas of whom $38.4 \%$ had symptoms for more than five years. ${ }^{7}$ Goldring et al recently reported a mean interval of 11 years from the onset of seizure to surgery that was mostly due to misinterpretation of abnormal computed tomograms as showing a non-neoplastic lesion. ${ }^{8}$ Thus the difficulties in making an early diagnosis are not confined to the United Kingdom.

We specially emphasise the importance of appreciating the seizure pattern. If the fit always begins in the same way regardless of how it may subsequently develop, it suggests a focal origin and focal pathology in the brain. Abnormalities on computed tomography were misinterpreted initially in four cases: two as focal atrophy, one as extensive scarring, and one as an arachnoid cyst. No radiological investigation was performed on one patient for five years. The most important feature, as we have already stressed, which suggests an indolent glioma rather than scarring or atrophy, is indentation of the vault adjacent to the tumour. This was present in seven of our eight cases. This may be visible on a plain skull radiograph as in three of our patients. Computed tomograms have also improved our ability not only to localise the tumour but also to detect calcification. Magnetic resonance imaging may have a role in further delineating the lesion in doubtful case, such as differentiating a tumour from atrophy or a cyst. ${ }^{9}$

The average duration of follow up was five years. It is important to follow up the patients for at least 12 months before one can evaluate the result of epi- 
lepsy surgery. Three of our cases had no further fits at review seven years later. One patient who was operated on seven months ago remains fit free. Another patient still has focal fits but with decreased frequency.

In this series there was no operative mortality. Pipemier reported two surgical deaths in 60 patients with low grade astrocytoma. ${ }^{7}$ The prognosis of indolent gliomas is generally favourable, but the tumour may perhaps become more aggressive after many years of quiescence. Complete excision can possibly achieve a 'cure'-as in two of our patients who have been followed up for seven years without recurrence.

It is a pleasure to thank Dr B Bower, Dr J Lindsay, and Dr G Stores who referred these patients to us.

\section{References}

${ }^{1}$ Penfield W, Jasper HH. Epilepsy and the functional anatomy of the human brain. Boston: Little, Brown and Co, 1954.
2 Falconer MA. Surgical and pathological aspects of temporal lobe epilepsy. Proc $R$ Soc Lond [Biol] 1953;46:971-4.

3 Thomas JE, Baker HL. Assessment of roentgenographic lucencies of the skull: a systematic approach. Neurology 1975;25:99106.

${ }^{4}$ Osborn RE, Ley CE. Astrocytoma with calvarial erosion. AJNR 1986;7:178.

5 Adams CBT. Temporal lobectomy in young people. In: Ross E, Chadwick D, Crawford R, eds. Epilepsy in young people. Chichester: John Wiley, 1986:103-11.

6 Page LK, Lombroso CT, Matson DD. Childhood epilepsy and late detection of cerebral glioma. J Neurosurg 1969;31:253-61.

${ }^{7}$ Pipemier AM. Observation on the current treatment of low grade astrocytic tumours of the cerebral hemispheres. J Neurosurg 1987;67:177-81.

${ }^{8}$ Goldring S, Rich K, Picker S. Experience with gliomas in patients presenting with a chronic seizure disorder. Clin Neurosurg 1986;33:15-42.

9 Sperling MR, Wilson G, Engel J, Babb TL, Phelps M, Bradley W. Magnetic resonance imaging in intractable partial epilepsy: correlative studies. Ann Neurol 1986;20:57-62.

Correspondence to $\mathrm{Mr}$ CBT Adams, Department of Neurosurgery, The Radcliffe Infirmary, Oxford OX2 6HE.

Accepted 12 July 1989 